\title{
Dimensión política de las decisiones en salud pública, Bogotá D.C., 2012-2013*
}

\section{Political Dimension of Public Health Decisions - Bogotá DC, 2012-2013}

\section{Dimensão política das decisões de saúde pública, Bogotá DC, 2012-2013}

Fecha de recepción: 15-11-13 Fecha de aceptación: 07-03-14

doi:10.11144/Javeriana.RGYPS13-26.dpds

Marisol Raigosa-Mejía**

Gloria Molina-Marín***

Artículo de investigación. Hace parte de los hallazgos de la investigación titulada "Decisiones en la política y la gestión en salud pública. Un análisis en seis ciudades colombinas en el contexto del Sistema General de Seguridad Social en Salud, 2012-2013". Las instituciones financiadoras de este estudio son: Colciencias, la Universidad de Antioquia y su Comité para el Desarrollo de la Investigación (CODI) - Sostenibilidad de grupos 2013-2014, Universidad Santo Tomás (sede Medellín), Universidad Nacional (sede Bogotá) y la Universidad de Illinois (Chicago, Estados Unidos). Fecha de inicio: febrero de 2012, fecha de finalización: marzo de 2014.

** Magíster en Políticas Públicas. Docente de Cátedra del Programa de Publicidad Internacional, Universidad Sergio Arboleda. Contratista de la Facultad Nacional de Salud Pública, Universidad de Antioquia. Dirección de correspondencia: Calle 74 \# 11-51, Casa Ciencias de la Comunicación, piso 2 - Universidad Sergio Arboleda, Bogotá (Colombia). Correo electrónico: mariraigo@yahoo.es

*** Doctora en Health Service Management. Docente, investigadora y coordinadora del Doctorado en Salud Pública, Facultad Nacional de Salud Pública, Universidad de Antioquia. Correo electrónico: molinag@saludpublica.udea. edu.co 


\section{Resumen}

Este artículo analiza la dimensión politica de las decisiones en salud pública en la ciudad de Bogotá D.C. (2012-2013), dentro del contexto del Sistema General de Seguridad Social en Salud (sGSss). Se exploró lo consagrado en la Constitución Política de Colombia de 1991, describiendo las condiciones del Estado social de derecho, el proceso de descentralización del sector salud, el surgimiento y evolución del sGSss y el lugar de la sP dentro de dicho sistema. Los hallazgos recogen elementos centrales de documentos de políticas públicas, que dejan ver tendencias del entorno político, económico y social en el ámbito local, relacionadas con la toma de decisiones en SP. Se destacan algunos progresos de la institucionalidad en la concepción de la salud como un derecho. No obstante, se requiere seguir avanzando en la administración del sistema de salud y en la gestión idónea, eficaz y transparente de las acciones en salud pública.

Palabras clave: sistema de salud; políticas públicas; mercado en salud; salud pública; modelos de atención en salud; determinantes sociales en salud

Palabras clave descriptor: sistemas de salud; políticas públicas; sector de atención de salud; salud pública; determinantes sociales de la salud

\section{Abstract}

This article analyzes the political dimension of decisions on public health in Bogotá DC (2012-2013) within the context of the General Social Security System (sGSs). Was explored as enshrined in the Constitution of Colombia of 1991, including the terms of the rule of law, decentralization of the health sector, the emergence and evolution of sGsss and place of the Public Health within that system. The findings contained core elements of public policy documents, which show trends of political, economic and social environment at the local level, related to decision -making in SP. Some progress of institutions highlighted in the concept of health as a right, however, further progress is required in the administration of the health system and the ideal, efficient and transparent management of public health actions.

Keywords: health system; public policy; market health; public health; models of health care; social determinants of health

Keywords plus: health system; public policies; health care sector; public health; social determinants of health

\section{Resumo}

Este artigo analisa a dimensão política das decisões sobre a saúde pública em Bogotá DC (2012-2013) no contexto do Sistema Geral de Previdência Social (sGSs). Foi explorado como consagrado na Constituição da Colômbia de 1991, incluindo os termos do Estado de Direito, a descentralização do setor da saúde, o surgimento e evolução da SGSSS e local da SP dentro desse sistema. Os resultados contidos elementos centrais de documentos de política pública, que mostram as tendências do ambiente político, económico e social a nível local, relacionados com a SP-tomada de decisão. Algum progresso das instituições se o conceito de saúde como um direito. No entanto, são necessários progressos suplementares na administração do sistema de saúde e de gestão ideal, eficiente e transparente das ações de saúde pública.

Palavras chave: sistema de saúde; políticas públicas; saúde do mercado; de saúde pública; os modelos de cuidados de saúde; determinantes sociais da saúde

Palavras chave descritores: sistemas de saúde; políticas públicas; setor de assistência à saúde; saúde públic; determinantes sociais da saúde 


\section{Introducción}

El aseguramiento dentro del Sistema General de Seguridad Social en Salud (sGSss), ha quedado instaurado como el instrumento a través del cual la población colombiana accede a un plan obligatorio de salud (POS), en el cual encuentra los servicios de promoción, prevención, tratamiento y rehabilitación. En consecuencia, con la normatividad establecida, se le encargó a las entidades territoriales y a las aseguradoras en salud, la tarea de llevar a cabo las políticas y programas de salud pública. Pese a esto, en el proceso de ejecución del SGSSS, Colombia concurrió a un detrimento en el suministro de programas y en los indicadores de SP, por razones asociadas al posicionamiento de actores copartícipes en el sistema, de un interés rentable que indujo el hecho de restarle importancia a la sP.

El objetivo principal de este artículo, es comprender el proceso de la toma de decisiones en la política y la gestión en SP y analizar específicamente la dimensión política de las decisiones en salud pública, tomando como punto de referencia la ciudad de Bogotá D.C. Asunto que se incluyó en la investigación "Decisiones en la política y la gestión en la salud pública en el ámbito municipal. Un análisis en seis ciudades colombianas en el contexto del Sistema General de Seguridad Social en Salud (sGsss) - (2012-2013)".

Para hacer posible el análisis de dicha dimensión, se examinó lo consagrado en la Constitución Política de Colombia de 1991, describiendo las condiciones del Estado social de derecho, el proceso de descentralización del sector salud, el surgimiento y evolución del sGsss y, específicamente, el lugar de la sP dentro de dicho sistema. La información se organizó a partir de un marco contextual que recogió las características principales de seis aspectos de análisis sobre los cuales se fueron definiendo las responsabilidades y acciones concretas de las entidades estatales relacionadas con la salud pública. Luego, se describe la metodología utilizada; posteriormente, se presentan los resultados a partir de la construcción de dos secciones de análisis. En cuarto lugar se mencionan las conclusiones generales del análisis realizado, poniéndolas en discusión con otros estudios de investigación que profundizan en asuntos de salud pública. Finalmente, las autoras presentan sus agradecimientos a las instituciones y personas que contribuyeron de una u otra manera con la realización del propósito inicial.

\section{Características del Estado social de derecho en materia de salud}

En el artículo primero de la Constitución Política de Colombia de 1991 se define al Estado colombiano como: un Estado social de derecho, organizado en forma de república unitaria, descentralizada, con autonomía de sus entidades territoriales, democrática, participativa y pluralista, fundamentado y orientado hacia el respeto de la dignidad humana, el trabajo y la solidaridad de las personas que lo componen y la prevalencia del interés general.

Como lo plantea González (1), el Estado social de derecho busca "la justicia social y la dignidad humana mediante la sujeción de las autoridades públicas a los principios, derechos y deberes sociales" (p. 20) de disposición constitucional, dado que acrecienta su criterio incorporando aspectos políticos, económicos, jurídicos y sociales. Agrega González que el adelanto del Estado social de derecho corresponde al reajuste histórico de sus reivindicaciones, "las cuales no son ajenas al crecimiento de la economía y a la activa participación de los ciudadanos y de sus organizaciones en el proceso democrático" (1, p. 21).

En materia de salud González (1, pp. 43-44) plantea que la satisfacción del más alto grado de salud que pueda alcanzar un 
ser humano es uno de los derechos fundamentales de los que no se puede despojar con ocasión de la raza, religión, ideología política o condición particular alguna. En este contexto, la salud abarca todas las actividades que están relacionadas con la prevención, promoción y protección e implica un enfoque integral, en donde se enlacen los escenarios físicos y sociales, económicos y culturales; en otros términos, todos los componentes que describen la existencia misma del ser humano. ${ }^{1}$

\section{Descentralización en salud y responsabili- dades en salud de los entes territoriales (2)}

En Colombia la descentralización inició en el sector salud desde finales de la década de los ochenta, específicamente en 1990, y luego avanzó a otros servicios públicos como la educación. Pero fue esencialmente con la Constitución Política de Colombia de 1991² (3) que el Gobierno introdujo un proceso de descentralización del Estado, como respuesta

1 En esta perspectiva, la Corte Constitucional ha entendido el derecho a la salud como la facultad que tiene todo ser humano de mantener la normalidad orgánica funcional, tanto física como mental, y de restaurarse cuando se presente un desajuste en su equilibrio biológico y funcional. Es por ello que este derecho conlleva una acción de preservación y otra de restablecimiento por parte del poder público, como de la sociedad, la familia y del individuo mismo (Sentencia T-484 de 1992, M.P.: Fabio Morón Díaz).

2 Con el cambio de perspectiva ocurrido con la Carta Política de 1991, de un Estado históricamente centralizado a un Estado distribuido en diversos territorios, se define expresamente en el artículo 286 de la Constitución que "son entidades territoriales los departamentos, los distritos, los municipios y los territorios indígenas". En consecuencia, el artículo 287 de la Constitución establece: "las entidades territoriales gozan de autonomía para la gestión de sus intereses, y dentro de los límites de la Constitución y la ley". Las entidades territoriales se definen por tres criterios básicos: político, administrativo y fiscal. Político, que les permite gobernarse por autoridades propias; administrativo, les permite ejercer las competencias que les correspondan; y fiscal, les permite participar en las rentas nacionales y establecer tributos necesarios para el cumplimiento de sus funciones (3, p. 21). a las exigencias políticas, sociales, administrativas y fiscales internas, y como requerimiento de los programas de ajuste estructural acordados con el Banco Mundial y el Fondo Monetario Internacional (FMI) que fomentaban la descentralización como una política pública pertinente para mejorar la eficiencia y la efectividad del Estado, con el objetivo de aumentar la cobertura, el acceso y la calidad de los servicios públicos (4, pp. 173-5).

Con la descentralización del sistema de salud colombiano, Ley 10 de 1990, se trasladaron las obligaciones de la prestación de servicios de salud a los gobiernos municipales y departamentales, sin tener en cuenta su categoría social y económica. Sin embargo, para conferir la certificación como entes descentralizados, los municipios y departamentos debían cumplir varias exigencias administrativas. Así, la descentralización implicó desarrollar y optimizar la capacidad institucional en los municipios e involucrar a la comunidad en la resolución de problemas públicos. El gobierno central dirige, regula y controla el sistema y de esta manera una nueva legislación (Ley 100 y Ley 60 de 1993, Ley 715 de 2001) ha venido fortaleciendo en las últimas dos décadas el proceso de descentralización.

La tabla 1 muestra la adjudicación de las competencias en salud pública, prestación de servicios y la administración de los impuestos para la salud de acuerdo con la legislación.

Para dar cumplimiento a las funciones anteriormente descritas, los municipios deben desplegar la capacidad institucional que les dé la posibilidad de gestionar los recursos, mejorando la eficiencia, la efectividad, la cobertura y la calidad de los servicios de salud. A su vez, deben instituir los dispositivos para alcanzar una participación efectiva de la comunidad en el transcurso de la prestación y el control de los servicios de salud. 
TABLA 1. COMPETENCIAS EN SALUd DE LOS TRES NIVELES DE GOBIERNO

\begin{tabular}{|c|c|c|}
\hline Gobierno central & Gobierno departamental & Gobierno municipal \\
\hline $\begin{array}{l}\text { - Formular políticas de salud } \\
\text { pública, prestación de } \\
\text { servicios, población objetivo } \\
\text { de los subsidios y un sistema } \\
\text { de información sobre salud. } \\
\text { - Establecer las prioridades del } \\
\text { Plan de Atención Básica de } \\
\text { Salud. } \\
\text { - Adoptar y proporcionar } \\
\text { las vacunas para el plan de } \\
\text { inmunización. } \\
\text { - Proporcionar asistencia } \\
\text { técnica a los departamentos. } \\
\text { - Distribuir y controlar los } \\
\text { recursos financieros. } \\
\text { - Realizar la vigilancia nacional } \\
\text { y el control de la salud pública } \\
\text { y la prestación de servicios. } \\
\text { - Proporcionar servicios } \\
\text { de salud altamente } \\
\text { especializados en conjunto } \\
\text { con otras agencias. }\end{array}$ & $\begin{array}{l}\text { - Adoptar e implementar } \\
\text { políticas de salud pública, } \\
\text { prestación de servicios y } \\
\text { distribución de recursos. } \\
\text { - Formular el Plan de } \\
\text { Atención Básica de Salud } \\
\text { departamental. } \\
\text { - Administrar la red de } \\
\text { servicios de salud por regiones } \\
\text { y prestar servicios de salud de } \\
\text { segundo y tercer nivel. } \\
\text { - Realizar la vigilancia } \\
\text { departamental y el control } \\
\text { de los servicios de salud, los } \\
\text { problemas de salud pública y } \\
\text { los recursos. } \\
\text { - Proporcionar asistencia } \\
\text { técnica a los municipios. } \\
\text { - Otorgar registro legal a las } \\
\text { instituciones de salud. } \\
\text { - Implementar el sistema de } \\
\text { información de salud. } \\
\text { - Distribuir y controlar los } \\
\text { recursos del Régimen } \\
\text { Subsidiado. }\end{array}$ & $\begin{array}{l}\text { - Adoptar e implementar } \\
\text { políticas de salud pública, } \\
\text { prestación de servicios y } \\
\text { asignación de subsidios a la } \\
\text { población objetivo. } \\
\text { - Formular y cumplir el Plan } \\
\text { de Atención Básica de Salud: } \\
\text { programas preventivos y de } \\
\text { promoción de la salud. } \\
\text { - Prestar servicios de salud } \\
\text { a la comunidad mediante } \\
\text { instituciones de su propiedad } \\
\text { o contratadas por el } \\
\text { municipio. } \\
\text { - Realizar la vigilancia y el } \\
\text { control de la salud pública y } \\
\text { de los servicios prestados por } \\
\text { las organizaciones sanitarias. } \\
\text { - Promover la creación de } \\
\text { organizaciones comunitarias } \\
\text { para participar y controlar la } \\
\text { calidad de los servicios. } \\
\text { - Implementar el sistema de } \\
\text { información sobre salud. } \\
\text { - Llevar a cabo la encuesta del } \\
\text { Sistema de Identificación de } \\
\text { Beneficiarios de Subsidios } \\
\text { (Sisben) y crear una base } \\
\text { de datos de la población de } \\
\text { acuerdo con la categoría } \\
\text { social y económica. } \\
\text { - Asignar los subsidios a la } \\
\text { población pobre. } \\
\text { - Contratar la prestación de } \\
\text { servicios para la población } \\
\text { pobre incluidos en el esquema } \\
\text { de subsidios. }\end{array}$ \\
\hline
\end{tabular}

Fuente: 4 (p. 174)

El Sistema General de Seguridad Social en Salud

El Sistema General de Seguridad Social en Salud (sgsss) de Colombia fue instaurado con la Ley 100 de 1993. De acuerdo con los planteamientos de Calderón et ál. (5, p. 2818), es un sistema de salud de competencia regulada, fundado en las mixturas públicaprivada y mercado-regulación, donde su 94 principal procedencia de financiamiento son las cotizaciones de empleados y empleado- res, que costean el régimen contributivo, y los recursos públicos adquiridos mediante impuestos generales que respaldan el régimen subsidiado. Las empresas promotoras de salud (EPS) son entidades aseguradoras públicas y privadas. Las instituciones prestadoras de servicios (IPS) se encargan de proveer los servicios de salud a los usuarios, de acuerdo con el contenido del pos. El Fondo de Solidaridad y Garantía (Fosyga) maneja los recursos financieros, paga a las EPS de acuerdo con el número de afiliados y 
el costo de la Unidad de Pago por Capitación (UPC), entre otros.

\section{Salud Pública en el Sistema General de Seguridad Social en Salud}

En el sGsss, la salud pública incluye las acciones colectivas orientadas a los grupos de población y el ambiente; acciones enfocadas en la promoción de la salud y la prevención de riesgos, contenidas en las normas y guías de detección temprana y protección específica, en cuyo desarrollo están involucrados los municipios y departamentos, las EPS e IPS públicas y privadas. El sGsss se cruzó con el proceso de descentralización, lo cual creó un intrincado sistema de relaciones de la nación con los departamentos, municipios y demás actores del SGSSs (5, p. 2821). Con el sGsss el desarrollo en salud pública ha sido negativo, específicamente hasta el año 2002, en la prevención y control de aquellas problemáticas para las cuales en el Sistema Nacional de Salud (sns) previo, se habían establecido programas verticales a nivel nacional, como las de vigilancia de enfermedades tropicales, tuberculosis, vacunación y otras semejantes.

Entre 2002 y 2006, con la Ley 715 de 2001 se reacomodó la asignación de recursos de la nación y los municipios. Durante este periodo se mejoraron un poco las acciones en sP en los departamentos y municipios. En el año 2000 se plantearon las normas y guías que indicaban las acciones de promoción, prevención y protección específica, hecho que permitió que se destinaran recursos específicos en estas (Resolución 412 de 2000).

A partir de 2007, se dio una reforma parcial de la Ley 100, por medio de la Ley 1122 de 2007 y la emisión del Plan Nacional de Salud Pública (PNSP) (Decreto 3039 de 2007), imperativo para todos los actores e instituciones. Este plan delimitó las competencias en sP para el nivel nacional, las entidades territoriales, y para todos los actores del sGsss, quienes además debían integrarse intersectorialmente, de acuerdo con lo especificado en el Plan Nacional de Desarrollo y en los planes de desarrollo territoriales. El PNSP se formuló en torno a cinco ejes de política: promoción de la salud y calidad de vida; prevención de los riesgos; recuperación y superación de los daños en la salud; vigilancia en salud y gestión del conocimiento y gestión integral para el desarrollo operativo y funcional del Plan Nacional de Salud Pública.

Estos ejes se concretan en objetivos, estrategias y metas, lo cual permite identificar resultados y aproximarse a la valoración de los impactos en salud (5, p. 2822). Pese a algunos adelantos, la sP sigue siendo el rubro que menor porcentaje de dinero recibe dentro de los diferentes usos en los que se destinan los recursos del sGsss (véase tabla 2).

TABLA 2. Usos DE LOS RECURSOS DEL SGSSS, 2009

\begin{tabular}{|l|c|c|}
\hline \multicolumn{1}{|c|}{ Usos } & Billones \$ & \% \\
\hline Régimen contributivo & 11.980 .593 & 39,8 \\
\hline Régimen subsidiado & 7.353 .578 & 24,4 \\
\hline Vinculados & 2.982 .655 & 9,9 \\
\hline Régimen especial & 1.900 .000 & 6,3 \\
\hline Salud pública & 1.512 .131 & 5,0 \\
\hline Otros usos & 4.407 .000 & 14,6 \\
\hline Total & $\mathbf{3 0 . 1 3 5 . 9 5 7}$ & $\mathbf{1 0 0}$ \\
\hline
\end{tabular}

Fuente: 5 (p. 2821) 
Del reducido nivel de inversión económica en sP se desprenden situaciones problemáticas en cuanto al acceso y calidad del servicio, la idoneidad del recurso humano que se contrata, debilidades en los sistemas de información, en la gestión de programas y proyectos, la atención primaria en salud (APS), entre otros.

\section{Partidos políticos y prácticas políticas}

Dentro de las caracterizaciones que se encuentran de la categoría partidos políticos, cabe citar algunos autores representativos en la materia (6). Max Weber (7, p. 228) denominó partido político a las: “... formas de socialización que, descansando en un reclutamiento (realmente) libre, tiene como fin proporcionar poder a sus dirigentes dentro de una asociación y otorgar por ese medio a sus miembros activos determinadas posibilidades ideales o materiales (la realización de bienes objetivos o el logro de ventajas personales o ambas cosas)".

Desde esta perspectiva, es necesario precisar que los miembros de los partidos políticos se adhieren voluntariamente y participan en ellos porque encuentran un mecanismo de integración. Con respecto al propósito de conceder y mantener el poder a los dirigentes, dentro y fuera del partido, cabe anotar que por un lado estos influyen en las decisiones políticas, administrativas y electorales del partido político y, por el otro, obtienen beneficios personales como prestigio, posición social, política, recursos económicos, entre otros; es decir, una doble apariencia que caracteriza las presunciones de los dirigentes y sus seguidores más cercanos (ver más en 8, p. 23).

Por su parte, Maurice Duverger aporta otro elemento fundamental dentro del concepto de partido político: el liderazgo. El autor establece dos figuras de líderes: "Los líderes son de diferente nivel, dan la dirección al partido y toman las decisiones en las áreas de incertidumbre. Dentro de los líderes existen dos categorías: los jefes reales son un grupo de líderes que monopolizan los cargos en la estructura, son quienes ejercen prácticamente el poder [...] los jefes aparentes tienen el poder teórico, son quienes representan al partido en las diferentes esferas de la actividad política" $(9$, p. 96$)$.

Los líderes reales son aquellos que tienen autoridad como precursores o líderes emblemáticos, tienen capacidad y potestad de elegir, implantar y advertir postulantes y personal cercano a ellos; lo que se conoce como relaciones informales. La contribución de Duverger considera la contingencia de que en el centro de los partidos políticos concurra un frente de poder, es decir, se respaldan los ordenamientos y estatutos consagrados, pero las prácticas o hábitos políticos están mediados por códigos no escritos que son obedecidos para la permanencia del partido (ver más en 8, p. 27-28).

\section{Políticas públicas: definiciones generales}

Algunas de las definiciones del concepto de política pública que acopia la literatura, plantean de manera habitual que una política pública es un fenómeno concreto de naturaleza social y política, que se instituye empíricamente y se construye de manera analítica. Otras definiciones expresan que una política pública es "la acción de las autoridades públicas en el seno de la sociedad" (10, p. 8). A su vez, Joan Subirats (11, p. 41) considera que las políticas públicas son un proceso de decisiones. Se decide sobre la existencia de un problema, sobre cómo se pretende resolver, sobre cuál es el modo más apropiado de proceder respecto a este y se decide crear una legislación. Además, reconoce que aunque la mayoría de las veces la sucesión no es tan racional como se describe en la teoría, todas las políticas públicas se soportan en un acumulado de decisiones que se relacionan entre sí. 
En esta misma lógica, Aguilar (12, p. 36) define las políticas públicas como decisiones de gobierno que adhieren el criterio, la participación, la corresponsabilidad y las finanzas de los ciudadanos, en su calidad de electores y contribuyentes. Desde esta configuración, se reduce el papel protagónico del Gobierno y se acrecienta el papel que desempeñan los individuos y las organizaciones, convergiendo así en una relación complementaria, en la cual gobierno y sociedad hacen frente a los problemas públicos de manera coordinada.

\section{Método e instrumentos}

\section{Tipo de estudio}

El análisis de los procesos de toma de decisiones en las políticas, la gestión en sP y la dimensión política en general, se llevó a cabo mediante un estudio de tipo cualitativo (13), para lo cual se utilizó como método la teoría fundamentada (14), cuyo acervo filosófico es el interaccionismo simbólico (15).

\section{Fuentes y técnicas de recolección de in- formación}

El estudio se llevó a cabo en seis ciudades de Colombia: Barranquilla, Bogotá, Bucaramanga, Leticia, Medellín y Pasto. Las técnicas de recolección de la información utilizadas fueron: entrevista individual (16) y grupo focal (17). Las entrevistas individuales se realizaron a profesionales de la salud o áreas afines vinculados a la toma de decisiones de nivel estratégico, de nivel intermedio y operativo (prestación de servicios) en sp. Es decir, personas de las secretarías de salud municipales, IPS, EPS públicas y privadas, organizaciones de la sociedad civil, Concejo Municipal, entidades de control y del sector académico.
Se efectuaron 102 entrevistas individuales en las seis ciudades mencionadas (aproximadamente 17 por ciudad). Un porcentaje alto de los entrevistados eran profesionales en enfermería, medicina y odontología; un porcentaje menor estuvo representado por profesionales en derecho y una amplia escala de técnicos y profesionales en contaduría, terapia ocupacional, bacteriología, psicología entre otros. El dato promedio de años de experiencia fluctúa entre tres y veintitrés años. Cabe mencionar que las entrevistas fueron realizadas en los lugares de trabajo, casa o algún lugar que brindara privacidad y un ambiente sereno al entrevistado y que permitiera una grabación de buena calidad.

También se realizaron 14 grupos focales con 64 participantes en total (un promedio de 5 personas por grupo). Dichos participantes eran líderes de organizaciones comunitarias, asociaciones de usuarios, ligas de pacientes, juntas administradoras locales y juntas de acción comunal. Un criterio de selección de los participantes fue que tuvieran al menos cuatro años de experiencia como representantes de organizaciones comunitarias en salud. Como característica que llama la atención, se destaca que la mayoría de los participantes eran personas de la tercera edad (61 años aproximadamente), además, con una media de 25 años como miembros de organizaciones comunitarias. Algunos de estos grupos focales contaron con la participación de profesionales del área de la salud, vinculados a instituciones públicas y privadas.

Se elaboraron y utilizaron guías de entrevistas semiestructuradas tanto para las entrevistas individuales como para los grupos focales. Las preguntas abordaron los siguientes ejes temáticos: aspectos personales y profesionales que intervienen en las decisiones en sP; relación de las decisiones en salud pública con la normatividad del sGsss; existencia de políticas y programas en SP y actores que 
participan en ellos; percepciones sobre el acceso y la calidad de los programas de sP; axiología en la praxis de la SP en el SGSSs y la participación comunitaria y papel de los partidos políticos en las decisiones en SP.

A los entrevistados se les explicaron los objetivos y la metodología de la investigación y se les solicitó su consentimiento informado; asimismo, se les garantizó la confiabilidad de la información, de su identidad y de la institución para la cual trabajaban.

\section{Análisis de la información}

Las entrevistas fueron grabadas y luego transcritas. Posteriormente, se realizó un análisis sistemático de codificación abierta, generando códigos independientes y códigos en vivo. Dicha codificación fue sometida a revisión, verificación, validación y discusión por parte de los investigadores del grupo de trabajo, buscando asegurar la calidad, validez y confiabilidad de esta y su categorización. Las categorías fueron discutidas por el equipo de investigación en pleno con el objetivo de advertir el fenómeno procedente y la correspondencia entre las diversas categorías. El producto de esta actividad de análisis fue el surgimiento de 13 categorías, cada una de ellas cimentada en 4-8 subcategorías relacionados con distintos asuntos del proceso de toma de decisiones en SP. Las nuevas categorías fueron organizadas en mapas conceptuales. Para el procesamiento y análisis de la información se hizo uso de los siguientes programas: World, Excel, Atlas.ti y CmapTools versión 4.16.

\section{Resultados}

En este artículo se presentan los hallazgos del estudio de la ciudad de Bogotá en cuanto a aspectos políticos de las decisiones en la política y la gestión en SP. Los resultados de todas la ciudades se han publicado en un libro titulado Tensiones en las decisiones en Salud Pública en el sistema de salud colombiano: El bien común en confrontación con los intereses y prácticas particulares (18).

En este apartado los resultados se analizaron a partir de dos secciones de análisis, el primero: la salud pública en los planes territoriales de salud, Bogotá 2008-2016 y el segundo: los acuerdos emitidos por el Concejo de Bogotá D.C. sobre asuntos de sP, entre 2008 y 2013.

\section{La Salud Pública en los planes territoriales de salud, Bogotá D. C.}

Los planes de desarrollo de 2008-2012 (19) y 2012-2016 (20) presentan los problemas de SP relevantes, el enfoque de salud, las líneas estratégicas, la identificación de la población priorizada en asuntos de SP, y los programas y proyectos que es necesario implementar por el ente territorial (véase tabla 3).

El Plan Territorial de Salud 2008-2012, del proyecto político del alcalde Samuel Moreno "Bogotá Positiva, para vivir mejor", se enfocó en la idea de crear espacios de vida donde rigieran la equidad y la dignidad, la garantía de los derechos universales y la generación de oportunidades reales para el disfrute de estos. Este plan intentó influir en los determinantes de la salud, entendiéndolos como un proceso que hace posible el desarrollo del proyecto vital humano, de las comunidades y de la sociedad en general. Se asume que el proceso salud-enfermedad se cristaliza en territorios sociales como contextos de interacción social y económica, expresado en las condiciones de vida de las personas y en sus distintas formas de vivir.

El Plan Territorial de Salud 2012-2016, del programa de gobierno del alcalde Gustavo Petro "Bogotá Humana", concibe la salud como la 
TABla 3. Planes territoriales de salud pública, Bogotá D.C.

\begin{tabular}{|c|c|c|}
\hline & $\begin{array}{c}\text { Plan territorial de salud } \\
\text { PTS 2008-2012 }\end{array}$ & $\begin{array}{c}\text { Plan territorial de salud } \\
\text { PTS 2012-2016 }\end{array}$ \\
\hline Enfoque(s) & $\begin{array}{l}\text { Modelo transectorial. Incluye las } \\
\text { intervenciones colectivas e individuales, } \\
\text { expresadas en los diferentes ejes } \\
\text { programáticos. La apuesta de la } \\
\text { administración fue impulsar en la Capital } \\
\text { estrategias para mejorar la calidad de vida } \\
\text { de la población, reconocer, garantizar } \\
\text { y restablecer los derechos humanos y } \\
\text { ambientales con criterios de universalidad } \\
\text { e integralidad. }\end{array}$ & $\begin{array}{l}\text { Modelo de atención integral } \\
\text { humanizado, participativo, } \\
\text { intersectorial e incluyente que permita } \\
\text { afectar positivamente los determinantes } \\
\text { de la calidad de vida y de la salud de } \\
\text { la población, así como garantizar el } \\
\text { acceso en condiciones de universalidad, } \\
\text { equidad, calidad y calidez a los servicios } \\
\text { de salud. }\end{array}$ \\
\hline $\begin{array}{l}\text { Líneas } \\
\text { estratégicas }\end{array}$ & $\begin{array}{l}\text {-Aseguramiento } \\
\text {-Prestación y desarrollo de servicios } \\
\text {-Salud Pública - Plan de Intervenciones } \\
\text { Colectivas } \\
\text {-Promoción Social } \\
\text {-Prevención, Vigilancia y Control de } \\
\text { Riesgos Profesionales } \\
\text {-Gestión de Riesgos frente a Urgencias, } \\
\text { Emergencias y Desastres }\end{array}$ & $\begin{array}{l}\text {-Gobernanza y rectoría } \\
\text {-Aseguramiento } \\
\text {-Prestación y desarrollo de servicios de } \\
\text { salud } \\
\text {-Salud pública } \\
\text {-Promoción social } \\
\text {-Prevención, vigilancia y control de } \\
\text { riesgos profesionales } \\
\text {-Urgencias, emergencias y desastres }\end{array}$ \\
\hline $\begin{array}{l}\text { Población } \\
\text { priorizada } \\
\text { en el plan en } \\
\text { asuntos de SP }\end{array}$ & $\begin{array}{l}\text {-Población por ciclo vital (Infancia, } \\
\text { juventud, adultez, persona mayor) } \\
\text {-Condiciones diferenciales (género, } \\
\text { discapacidad, habitante de calle, condición } \\
\text { de desplazamiento, reinsertados y } \\
\text { desmovilizados). } \\
\text {-Niños y adolescentes en protección y } \\
\text { población institucionalizada. }\end{array}$ & $\begin{array}{l}\text {-Primera infancia (niños(as) de } 0 \text { a } 5 \\
\text { años) } \\
\text {-Atención integral a víctimas del } \\
\text { conflicto armado } \\
\text {-Minorías étnicas }\end{array}$ \\
\hline $\begin{array}{l}\text { Programas } \\
\text { y proyectos } \\
\text { implemen- } \\
\text { tados por el } \\
\text { ente territo- } \\
\text { rial en sp }\end{array}$ & $\begin{array}{l}\text {-Plan de Intervenciones Colectivas (PIC) } \\
\text {-Toda la vida integralmente protegida } \\
\text { Proyectos } \\
\text {-Campañas de vacunación infantil } \\
\text {-Jóvenes visibles, con derechos y } \\
\text { responsabilidad } \\
\text {-Bono económico adulto mayor } \\
\text {-Programa para la reducción de la } \\
\text { violencia intrafamiliar } \\
\text {-Atención integral a la primera infancia } \\
\text { expuesta a situaciones de vulneración de } \\
\text { derechos }\end{array}$ & $\begin{array}{l}\text { Programa } \\
\text {-Territorios Saludables y Red Pública de } \\
\text { Salud para la Vida } \\
\text { Proyectos } \\
\text {-Hospital San Juan de Dios } \\
\text {-Salud Humana } \\
\text {-Acceso universal y efectivo a la salud } \\
\text {-Integración en redes para la salud } \\
\text {-Conocimiento para la salud } \\
\text {-Instituto de biotecnología } \\
\text {-Modernización de servicios de salud } \\
\text {-Urgencias y emergencias } \\
\text {-Salud en línea }\end{array}$ \\
\hline
\end{tabular}

Fuente: Planes territoriales de salud, Bogotá D. C., 2008-2012 (21) y 2012-2016 (22)

firme defensa de este derecho, aspecto que a diferencia de otras administraciones y en concordancia con el enfoque de determinantes, se asume de manera más directa e integral desde la administración central, y por ende desde la Secretaría Distrital de Salud de Bogotá D. C., sus entidades adscritas y organismos públicos como el Consejo Territorial de Seguridad Social en Salud, la Empresa Promotora de Salud (EPS) Capital Salud y la red de empresas sociales del Estado, entre otras, que trabajaron para lograr la solución de problemas que afectan a la población, en un modelo de salud, de gestión y de atención integral. 
La salud se entiende como un derecho fundamental, y con ello se comprometió la Administración de Bogotá Humana, llevando a cabo acciones que buscan permitir la apropiación y el empoderamiento de la ciudadanía en todo el proceso de toma de decisiones. Esto incluye los cabildos y presupuestos participativos como mecanismos por medio de los cuales los ciudadanos tienen la posibilidad de decidir sobre la disposición y ejecución del presupuesto de su localidad y de su territorio, junto con la correspondiente rendición de cuentas por parte de los funcionarios públicos sobre el manejo trasparente de los recursos de la salud.

Los modelos de atención y abordajes de la sp que las autoridades de salud han puesto en marcha, principalmente durante los últimos 10 años, han enfrentado serias limitaciones derivadas de la fragmentación de la atención y de la estructura organizativa del sGsss, del modelo de aseguramiento, del mercado competitivo reinante en el sistema de salud, así como del ánimo de lucro de los actores privados vinculados al aseguramiento de la prestación de servicios, lo cual los lleva a la no acción en sP y a evadir sus responsabilidades en este campo.

Otro aspecto que destacar de los hallazgos es la interferencia de las prácticas políticas tradicionales en las decisiones y la gestión en SP -prácticas estas que son expresión de los intereses clientelistas y particulares de los dirigentes de algunas entidades públicas y privadas-, así como la pugna por los contratos para obtener recursos y prebendas. Igualmente, dentro de los imaginaros culturales cabe resaltar una falta de conciencia de lo público, tanto en los funcionarios como en la ciudadanía; en consecuencia, la salud es asumida como un favor político y no como un derecho fundamental.
Esto, sumado al fenómeno de la corrupción, problemática de profunda y amplia envergadura en el sGsss. Por ejemplo, en las EPS este asunto ha empezado a hacerse cada vez más visible, permeando la toma de decisiones en la asignación de recursos, en la adjudicación de licitaciones para ejecutar proyectos en SP y en las ganancias de los intermediarios, que se apropian del recurso económico destinado a este fin, entre otros. También es necesario mencionar el abuso del poder de algunos actores para lograr beneficio propio, lo que finalmente afecta la prestación de los servicios de salud y reproduce las inequidades y el incumpliendo con los programas establecidos, debido a la desviación de recursos.

\section{Acuerdos emitidos por el Concejo de Bogotá sobre asuntos de salud pública}

Para ejercer sus funciones, el Concejo Distrital está dividido en tres comisiones: Comisión de Gobierno, Comisión de Hacienda y Comisión del Plan. Dentro de esta última se incluye el tema de salud y por ende ella gestiona la generación de acuerdos que hacen referencia directa o indirecta a los asuntos que comprometen la salud de los habitantes de Bogotá. Se revisaron los acuerdos aprobados por el Concejo de Bogotá a partir del año 2008 y hasta abril del 2013, identificando en ellos el número del acuerdo, la población hacia la cual iban dirigidas las acciones decretadas, los asuntos de sP abordados y las acciones de implementación del acuerdo (ver tabla 4).

Dentro de los acuerdos aprobados cabe resaltar acciones concretas tales como: el Plan de Territorios Saludables y Red Pública de Salud para la Vida, las estrategias integrales de promoción de alimentación saludable, las de promoción para la higiene de manos y las prácticas sostenibles para la reducción de dioxinas. 


\section{Conclusiones y discusión}

Los resultados presentados permiten las siguientes conclusiones:

- La salud en general y la sP en particular han estado en la agenda política de los gobiernos distritales del periodo analizado, de las autoridades de salud y del Concejo de Bogotá, de lo cual dan cuenta los pla- nes de desarrollo revisados y los acuerdos emitidos por el Cabildo Distrital.

- Las autoridades de salud han entendido la salud como un asunto multidimensional, relacionado con y determinado por factores económicos, políticos, sociales, culturales e institucionales, y le han apostado a modelos de salud fundamentados en diferentes enfoques teóricos y meto-

TABla 4. Acuerdos del Concejo de Bogotá sobre asuntos de Salud Pública 2008-2013

\begin{tabular}{|c|c|c|c|c|}
\hline $\begin{array}{c}\text { Número } \\
\text { del } \\
\text { acuerdo }\end{array}$ & $\begin{array}{c}\text { Año de } \\
\text { Apro- } \\
\text { bación }\end{array}$ & Población Objeto & $\begin{array}{l}\text { Tema de salud pú- } \\
\text { blica que aborda }\end{array}$ & Acciones de implementación \\
\hline 334 & 2008 & $\begin{array}{l}\text { Usuarios del } \\
\text { servicio masivo } \\
\text { de transporte } \\
\text { Transmilenio }\end{array}$ & $\begin{array}{l}\text { Ausencia de equi- } \\
\text { pos de salud en los } \\
\text { portales y estacio- } \\
\text { nes de Transmilenio }\end{array}$ & $\begin{array}{l}\text { Instalación, dotación, mantenimiento y } \\
\text { uso del botiquín de primeros auxilios. } \\
\text { Entrenamiento y capacitación al } \\
\text { personal del Sistema Transmilenio } \\
\text { para que sus representantes sean los } \\
\text { primeros en responder y en activar el } \\
\text { Sistema de Emergencias Médicas. }\end{array}$ \\
\hline 379 & 2009 & $\begin{array}{l}\text { Mujeres entre } 10 \\
\text { y } 49 \text { años }\end{array}$ & $\begin{array}{l}\text { Programa Anual } \\
\text { de Promoción } \\
\text { del Refuerzo del } \\
\text { Esquema Comple- } \\
\text { to de Vacunación } \\
\text { (enfermedades } \\
\text { inmunoprevenibles) } \\
\text { "PAI" }\end{array}$ & $\begin{array}{l}\text { La Secretaría Distrital de Salud y } \\
\text { la de Educación impulsan en los } \\
\text { colegios distritales, centros de Salud y } \\
\text { Empresas Sociales del Estado (ESE), la } \\
\text { aplicación del esquema de vacunación } \\
\text { "PAI". }\end{array}$ \\
\hline 461 & 2010 & $\begin{array}{l}\text { Se deberá garan- } \\
\text { tizar la vacuna } \\
\text { contra el virus } \\
\text { del papiloma hu- } \\
\text { mano (VPH), de } \\
\text { manera gratuita } \\
\text { a la población } \\
\text { que la Secreta- } \\
\text { ría Distrital de } \\
\text { Salud considere } \\
\text { conveniente, con } \\
\text { previa autori- } \\
\text { zación de los } \\
\text { padres de familia } \\
\text { o quien tenga la } \\
\text { custodia de la } \\
\text { adolescente }\end{array}$ & $\begin{array}{l}\text { Incorporar dentro } \\
\text { del programa } \\
\text { de "Detección y } \\
\text { Control de Cáncer } \\
\text { de Cuello Uterino" } \\
\text { medidas para la } \\
\text { prevención del VPH }\end{array}$ & 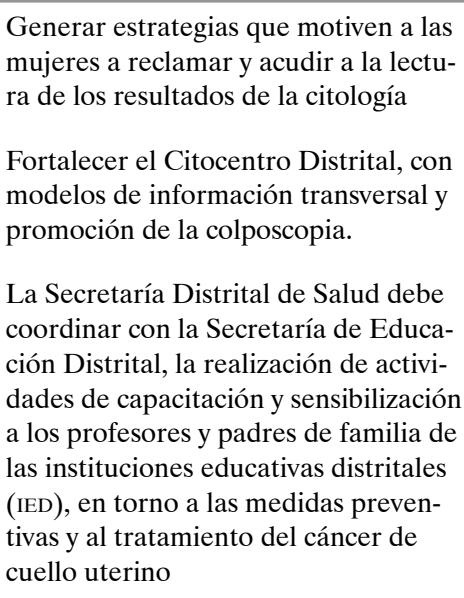 \\
\hline
\end{tabular}




\begin{tabular}{|c|c|c|c|c|}
\hline $\begin{array}{l}\text { Núme- } \\
\text { ro de } \\
\text { acuerdo }\end{array}$ & $\begin{array}{l}\text { Año de } \\
\text { Apro- } \\
\text { bación }\end{array}$ & Población objeto & $\begin{array}{l}\text { Tema de salud pú- } \\
\text { blica que aborda }\end{array}$ & Acciones de implementación \\
\hline 462 & 2010 & $\begin{array}{l}\text { Toda persona } \\
\text { que desempeñe } \\
\text { alguna de las ac- } \\
\text { tividades de que } \\
\text { trata el presente } \\
\text { acuerdo }\end{array}$ & $\begin{array}{l}\text { Lineamientos en ma- } \\
\text { teria de bioseguridad } \\
\text { para los establecimien- } \\
\text { tos que ofrecen servi- } \\
\text { cios de: estética facial } \\
\text { y corporal, gimnasios, } \\
\text { saunas, turcos, salas de } \\
\text { masajes y estableci- } \\
\text { mientos afines en el } \\
\text { Distrito Capital }\end{array}$ & $\begin{array}{l}\text { Acreditar formación en bioseguridad, } \\
\text { dentro del marco legal vigente, que le } \\
\text { permita identificar, evaluar y contro- } \\
\text { lar los diferentes factores de riesgos } \\
\text { biológicos y ocupacionales generado- } \\
\text { res de enfermedades ocupacionales y } \\
\text { saneamiento básico }\end{array}$ \\
\hline 489 & 2012 & $\begin{array}{l}\text { Todos los } \\
\text { habitantes del } \\
\text { Distrito Capital, } \\
\text { sin excepción }\end{array}$ & $\begin{array}{l}\text { Se adopta el Plan de } \\
\text { Desarrollo Económico, } \\
\text { Social, Ambiental y de } \\
\text { Obras Públicas para } \\
\text { Bogotá D.C. 2012-2016 } \\
\text { - Bogotá Humana” }\end{array}$ & $\begin{array}{l}\text { Territorios saludables y red de salud } \\
\text { para la vida desde la diversidad }\end{array}$ \\
\hline 498 & 2012 & $\begin{array}{l}\text { Población } \\
\text { expuesta a/o } \\
\text { con problemas } \\
\text { de sobrepeso y } \\
\text { obesidad }\end{array}$ & $\begin{array}{l}\text { Problemas de so- } \\
\text { brepeso y obesidad } \\
\text { (23) }\end{array}$ & $\begin{array}{l}\text { Estrategias integrales de promoción } \\
\text { de alimentación saludable y de activi- } \\
\text { dad física que mejoren la calidad de } \\
\text { vida y la salud }\end{array}$ \\
\hline $\mathbf{5 0 7}$ & 2012 & $\begin{array}{l}\text { Gratuito para } \\
\text { población pobre } \\
\text { y vulnerable no } \\
\text { asegurada }\end{array}$ & $\begin{array}{l}\text { Dificultades en la } \\
\text { búsqueda temprana } \\
\text { de enfermedades que } \\
\text { no son fácilmente de- } \\
\text { tectadas en las prime- } \\
\text { ras semanas de vida } \\
\text { y que pueden tener } \\
\text { graves consecuencias } \\
\text { en un futuro }\end{array}$ & $\begin{array}{l}\text { Tamizaje universal neonatal auditivo y } \\
\text { visual en el Distrito Capital }\end{array}$ \\
\hline 508 & 2012 & $\begin{array}{l}\text { Mujeres en esta- } \\
\text { do de embarazo y } \\
\text { parejas que asis- } \\
\text { ten a los cursos } \\
\text { psicoprofilácticos }\end{array}$ & $\begin{array}{l}\text { Dificultades sociales } \\
\text { y familiares por causa } \\
\text { de debilidades en la } \\
\text { paternidad y materni- } \\
\text { dad responsables }\end{array}$ & $\begin{array}{l}\text { Acciones de promoción en los cursos } \\
\text { psicoprofilácticos }\end{array}$ \\
\hline 512 & 2012 & $\begin{array}{l}\text { Niños(as) y } \\
\text { jóvenes en edad } \\
\text { escolar }\end{array}$ & $\begin{array}{l}\text { Falta de higiene } \\
\text { de manos y otras } \\
\text { disposiciones } \\
\text { (cambio cultural } \\
\text { respecto al cuidado } \\
\text { en salud) (24) }\end{array}$ & $\begin{array}{l}\text { Estrategia integral para la promoción } \\
\text { de la higiene de manos }\end{array}$ \\
\hline 513 & 2012 & $\begin{array}{l}\text { Todos los habitan- } \\
\text { tes del Distrito Ca- } \\
\text { pital, sin excepción }\end{array}$ & $\begin{array}{l}\text { Exposición a } \\
\text { dioxinas }\end{array}$ & $\begin{array}{l}\text { Prácticas ambientalmente sostenibles } \\
\text { para la reducción de dioxinas }\end{array}$ \\
\hline 520 & 2013 & $\begin{array}{l}\text { Todas las mujeres } \\
\text { en edad reproducti- } \\
\text { va que se realicen el } \\
\text { examen de citología }\end{array}$ & $\begin{array}{l}\text { Dificultades para } \\
\text { enviar resultados } \\
\text { de los exámenes de } \\
\text { citología }\end{array}$ & $\begin{array}{l}\text { Programa de detección y control del } \\
\text { cáncer de cuello uterino. A través } \\
\text { de las tecnologías de información y } \\
\text { comunicación disponible }\end{array}$ \\
\hline
\end{tabular}

Fuente: Planes territoriales de salud, Bogotá D. C., 2008-2012 (21) y 2012-2016 (22) 
dológicos tales como los determinantes sociales de la salud, los derechos y la Atención Primaria en Salud.

- Los partidos políticos con sus prácticas clientelares y los intereses de agentes privados interfieren en los procesos de toma de decisiones en sp. Con ello afectan la asignación y utilización de los recursos y el desarrollo de los programas y proyectos en este campo.

- Las prácticas de corrupción con los recursos asignados para sp las hacen tanto las entidades privadas -aseguradoras y prestadoras- como las entidades públicas, y dependen de los vínculos clientelares propiciados por los partidos políticos y sus alianzas con agentes privados y entes de vigilancia y control.

De la producción de literatura nacional sobre los estudios de políticas públicas acerca de la salud en general (25) y de la sp en particular (26), es importante reconocer el trabajo Políticas públicas y salud: relación entre investigación y decisión, realizado por Rubén D. Gómez et ál. (27, p. 105-18), que explora la relación entre la investigación y las políticas en salud, determinando condiciones y tendencias que permitirían mejorar la intervención de los investigadores con relación a las políticas en el tema. Se plantea que mediante diversos modelos se pretende dar cuenta de las relaciones entre investigaciones y políticas.

Sin embargo, estos se quedan cortos para explicar por qué algunas interacciones son exitosas y otras no. Se reconoce que tanto la investigación como la gestión de las políticas son procesos dinámicos, que no ocurren siempre de igual manera, y cuyos puntos de convergencia se relacionan con cinco dimensiones: el tema central al que ambas se refieren, las características personales de los investigadores y los políticos, la manera como ambos desempeñan su papel, las presiones del contexto sociopolítico sobre investigadores y políticos y el impacto potencial de los hallazgos.

Desde las instituciones del Estado ha habido iniciativas de proponer nuevas perspectivas teóricas y metodológicas para la construcción de las políticas públicas, como sucede en la Secretaría Distrital de Salud de Bogotá, que de acuerdo con los planteamientos de Solángel García et ál. (28, pp. 129-42), estos esfuerzos se han venido fortaleciendo en las dos últimas décadas. Las primeras propuestas constituyeron marcos de referencia filosóficos y éticos que intentaban dar orientaciones para el proceder de los diferentes sectores. En los últimos seis años, las políticas empezaron a regularse por acuerdos del Concejo de la ciudad o por decretos de la Alcaldía. Hoy en día se identifican cerca de 14 políticas públicas relacionadas directamente con las personas, es decir, se crearon para un grupo de población con alguna característica particular en el contexto de las políticas de focalización o enfoque diferencial (28, p. 129).

De acuerdo con los planteamientos de García y con la información que se halló en los planes de desarrollo de Bogotá, se puede afirmar que en los últimos ocho años las autoridades de salud de la ciudad le han apostado a diversos enfoques de salud, tales como los determinantes sociales en salud, el ciclo vital humano, los derechos, entornos saludables, entre otros, lo que ha conllevado una orientación multisectorial e interdisciplinar. Desde esta perspectiva, se entiende la salud como un derecho y un concepto unido al desarrollo social, que requiere para su defensa la participación y corresponsabilidad del individuo, la familia, la comunidad y el Estado.

La estrategia de Entornos Saludables (29) ha permitido vislumbrar la fundamentación de las políticas públicas saludables como un dispositivo de carácter no exclusivo del 
sector salud, comprendiendo premisas tales como: la salud abarca mucho más que la ausencia de enfermedad, el entorno es el espacio-tiempo en el que se desarrolla el ser vivo, y el ambiente es aquel que contiene los recursos naturales y contempla las relaciones sociopolíticas y económicas que se gestan en su interior. La propuesta de integrar la estrategia de Entornos Saludables a los procesos de política pública se desplegó como un método de desarrollo progresivo (30) que vinculó el tema de salud a la agenda política intersectorial y concibió transformaciones en la organización ciudadana y, al mismo tiempo, orientó el diseño de propuestas acordes al contexto de influencia.

Los acuerdos aprobados por el Concejo de la ciudad dejan ver una intención de favorecer a todos los habitantes de Bogotá, especialmente a la población de más bajos recursos económicos, en el acceso a las dotaciones y capacidades que les permitan gozar de condiciones de vida que superen los niveles de subsistencia básica, con independencia de su identidad de género, orientación sexual, condición étnica, preferencias políticas, culturales, etc., sin decir con ello que en la realidad la aplicación de dicha legislación se cumpla a cabalidad.

Sin embargo, pese a los esfuerzos por intervenir en las decisiones de la gestión pública, en Colombia continúa persistiendo un debilitamiento de las instituciones y del Estado de derecho, donde las entidades encargadas de la salud no son la excepción. En la última década ha prevalecido "una configuración institucional desequilibrada a favor del poder ejecutivo y del sector privado [...] y a un fortalecimiento del estilo pactista de gobernabilidad que consiste en negociar de manera clientelista con las élites privadas..." (31, p. 17). Estas prácticas políticas tradicionales (corrupción, gamonalismo, clientelismo) que minan las instituciones del Estado, solo podrían disminuirse si se fortalece una participación ciudadana autónoma y democrática (31, p. 217).

\section{Agradecimientos}

Las autoras hacen una mención especial de aquellas personas entrevistadas, organizaciones comunitarias e instituciones que contribuyeron a hacer posible la realización de esta investigación. Agradecemos también a las instituciones financiadoras de este estudio: Colciencias, Universidad de Antioquia y su Comité para el Desarrollo de la Investigación (CODI)-Sostenibilidad de Grupos 2013-2014, Universidad Santo Tomás (sede Medellín), Universidad Nacional (sede Bogotá) y la Universidad de Illinois (Chicago, Estados Unidos).

\section{Referencias bibliográficas}

1. González A. El Estado Social de Derecho en la protección del derecho a la vida y la salud de la mujer embarazada [tesis de maestría]. Bogotá: Facultad de Ciencias Políticas y Relaciones Internacionales, Pontificia Universidad Javeriana; 2007.

2. Gutiérrez F. Instituciones y territorio. La descentralización en Colombia. En: Jost S. 25 años de la descentralización en Colombia. Bogotá: Konrad Adenauer Stiftung; 2010. p. 11-54.

3. Mesa CA, Remolina JP, Pérez AC, Igua DM. Descentralización y entidades territoriales. Bogotá: Instituto de Estudios del Ministerio Público (IEMP) y Procuraduría General de la Nación; 2011.

4. Molina G, Spurgeon P. La descentralización del sector salud en Colombia. Una perspectiva desde múltiples ámbitos. Revista Gestión y Política Pública. 2007; (1): 171-202.

5. Calderón C, Bacigalupe A, Esnaola S, Zuazagoitia J, Aldasoro E. La investigación cualitativa en la evaluación del impacto en la salud: La experiencia de un plan de reforma en un barrio de Bilbao. Revista Facultad Nacional de Salud Pública. 2009. 27 (1): 45-9.

6. Sartori G. Partidos y Sistemas de partidos. Madrid: Alianza Universidad; 1992.

7. Weber M. Economía y sociedad. México D.F.: Alianza; 2009.

8. Navarrete JP. Partidos políticos y campañas electorales. Tlalnepantla de Baz: Red Tercer Milenio; 2012. 
9. Duverger M. Los partidos políticos. México D.F.: Fondo de Cultura Económica; 1981.

10. Meny I, Thoenig JC. Les politiques publiques. París: PUF; 1989.

11. Subirats J. Análisis de políticas públicas y eficacia de la Administración. Madrid: Ministerio para las Administraciones Públicas; 1989.

12. Aguilar LF. El estudio de las políticas públicas. México D.F.: Porrúa; 1992.

13. Strauss A, Corbin J. Bases de la investigación cualitativa técnicas y procedimientos para desarrollar la teoría fundamentada. Medellín: Editorial Universidad de Antioquia; 2002.

14. Inciarte A, facilitador. Seminario: Generación de teoría - Teoría fundamentada. Puerto Ordaz: Facultad de Humanidades y Educación, División de Estudios para Graduados, Doctorado en Ciencias Humanas, Universidad del Zulia; 2011.

15. Blummer H. El interaccionismo simbólico: perspectiva y método. Barcelona: Hora; 1982.

16. Taylor S, Bogdan R. Introducción a los métodos cualitativos en investigación. La búsqueda de los significados. Nueva York: Paidós; 1992.

17. Dreachslin, J. Conducting effective focus groups in the context of diversity: Theoretical underpinnings and practical implications. Qualitative Health Research. 1998; 8 (3): 813-20.

18. Molina G, Ramírez A, Ruiz AM, editores académicos. Tensiones en las decisiones en salud pública en el sistema de salud colombiano: El bien común con los intereses y prácticas particulares. Medellín: Pulso y Letra Editores; 2014.

19. Moreno S. Plan de Desarrollo 2012-2016 Bogotá Humana. Bogotá Alcaldía Mayor; 2008.

20. Petro G. Plan de Desarrollo 2008-2012 Bogotá Positiva: para vivir mejor. Bogotá: Alcaldía Mayor; 2012.

21. Zambrano H. Plan Territorial de Salud Bogotá Distrito Capital 2008-2012. Bogotá: Secretaría Distrital de Salud; 2008.

22. Jaramillo GA. Plan Territorial de Salud Bogotá Distrito Capital 2012-2016. Bogotá: Secretaría Distrital de Salud; 2012.
23. Álvarez C, Lara VC, González R, Ortiz G. Opciones de política pública para afrontar la obesidad - Proyecto ProGrow, Unión Europea. Alicante, España: Departamento de Salud Pública, Universidad de Alicante, Observatorio de Políticas Públicas y Salud (opps); 2006.

24. Organización Mundial de la Salud (oms). Programa mundial de la oms de Investigaciones de salud pública sobre la gripe. Ginebra: Ediciones de la oms; 2009.

25. Molina G, Cabrera G, compiladores. Políticas públicas en salud: aproximación a un análisis. Medellín: Facultad Nacional de Salud Pública "Héctor Abad Gómez”, Universidad de Antioquia; 2009.

26. Arenas G, coordinadora. La gestión del conocimiento para la salud pública - Plan Estratégico de Antioquia (Planea). Medellín: Red Colombiana de Investigación en Políticas y Sistemas de Salud; 2009.

27. Gómez RD, Orozco DA, Rodríguez FL, Velázquez W. Políticas públicas y salud: relación entre investigación y decisión. Revista Facultad Nacional de Salud Pública. 2006; 24 (2): 105-18.

28. García S, Ruiz E, Díaz T, Rozo P, Espinosa G. El enfoque poblacional: las personas como centro de las políticas. Revista de Investigaciones en Seguridad Social y Salud. 2010; (12): 129-42.

29. Rodríguez LF, Díaz MF. Políticas públicas y entornos saludables. Bogotá: Facultad de Rehabilitación y Desarrollo Humano, Editorial Universidad del Rosario; 2009.

30. Alleyne A, Casas JA. La evaluación del impacto de la salud como una herramienta para la promoción de la salud y las políticas públicas. En: Health Canada International Affairs Directorate, División Salud y Desarrollo Humano, Organización Panamericana de la Salud, Oficina Sanitaria Panamericana, Oficina Regional de la Organización Mundial de la Salud. Salud de la población: Conceptos y estrategias para políticas públicas saludables "La perspectiva canadiense". Washington, D.C. 2000. p. 62-102.

31. García M, Revelo JE. Estado alterado. Clientelismo, mafias y debilidad institucional en Colombia. Bogotá: Colección de Justicia; 2010. 